\title{
REAL TIME PSYCHROMETRIC DATA COLLECTION
}

\author{
Kirk H. McDaniel, P.E. \\ Senior Engineer, \\ Westinghouse Electric Corporation, \\ Waste Isolation Division, \\ Carlsbad, NM.
}
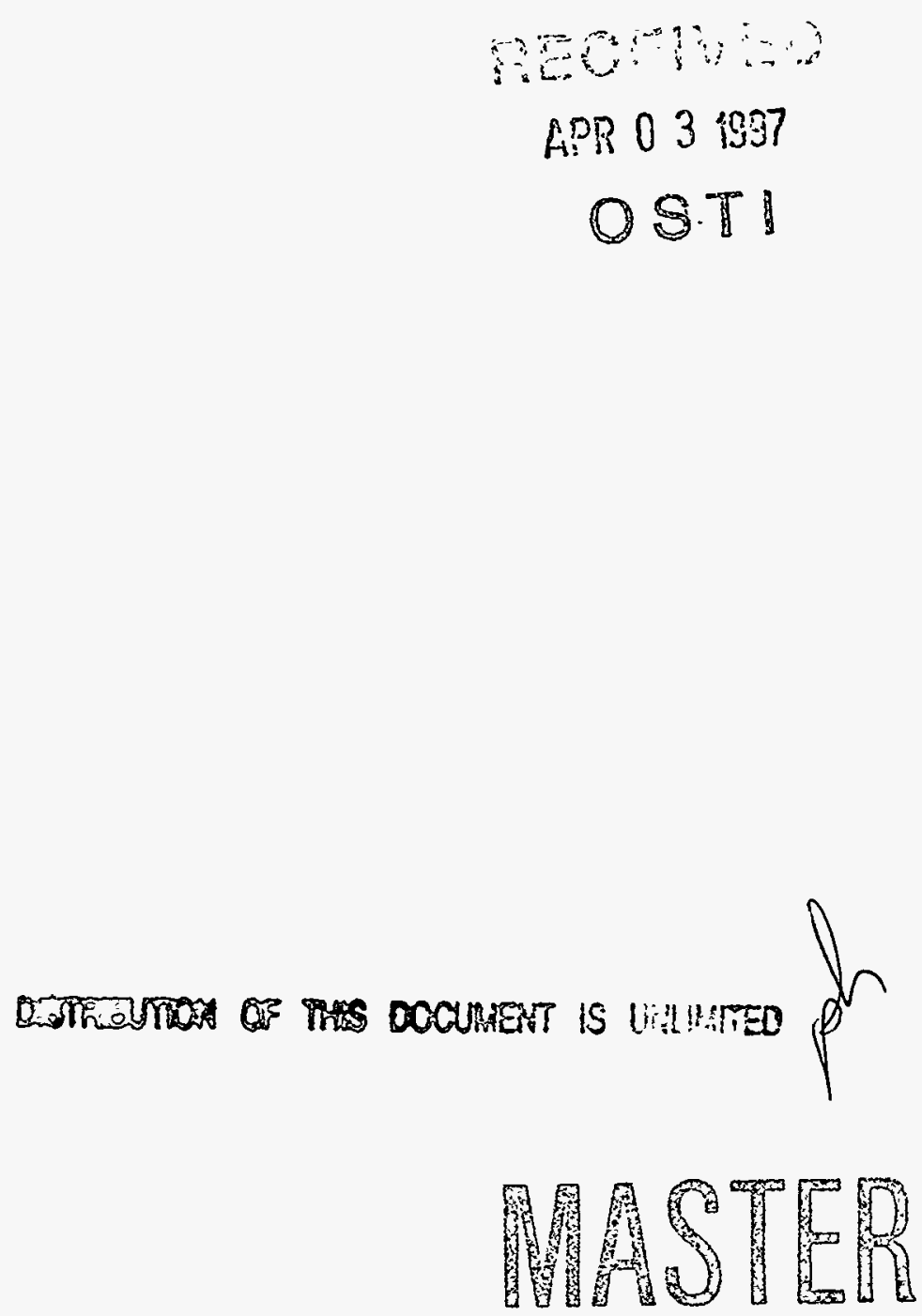

Processing and final preparation of this report was performed by the Waste Isolation Pilot Plant Management and Operating Contractor for the U.S. Department of Energy under Contract No. DE-ACO4-86AL31950. 


\section{DISCLAMMIER}

Portions of this document may be illegible in electronic image products. Images are produced from the best avaliable original document. 


\section{DISCLAIMER}

This report was prepared as an account of work sponsored by an agency of the United States Government. Neither the United States Government nor any agency thereof, nor any of their employees, make any warranty, express or implied, or assumes any legal liability or responsibility for the accuracy, completeness, or usefulness of any information, apparatus, product, or process disclosed, or represents that its use would not infringe privately owned rights. Reference herein to any specific commercial product, process, or service by trade name, trademark, manufacturer, or otherwise does not necessarily constitute or imply its endorsement, recommendation, or favoring by the United States Government or any agency thereof. The views and opinions of authors expressed herein do not necessarily state or reflect those of the United States Government or any agency thereof. 
This document has been reproduced directly from the best possible copy.

It is avaliable to DOE and DOE contractors at the following addresses:

Office of Scientific and Technical Information

P.O. Box 62

Oak Ridge, TN 37831

Prices available from (615) 576-8401

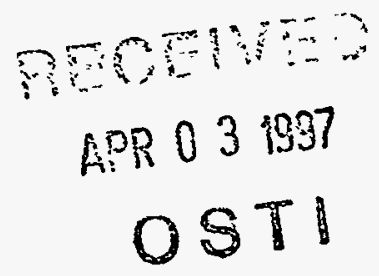

Available to the public from the National Technical Information Services

U. S. Department of Commerce 5285 Port Royal Road Springfield, VA 22161

Processing and final preparation of this report was performed by the Waste Isolation Pilot Plant Management and Operating Contractor for the U.S. Department of Energy under Contract No. DE-ACO4-86AL31950. 
ABSTRACT Eight Mine Weather Stations (MWS) installed at the Waste Isolation Pilot Plant (WIPP) to monitor the underground ventilation system are helping to simulate real-time ventilation scenarios. Seasonal weather extremes can result in variations of Natural Ventilation Pressure (NVP) which can significantly effect the ventilation system. The eight MWS(s) (which previously collected and stored temperature, barometric pressure and relative humidity data for subsequent NVP calculations) were upgraded to provide continuous real-time data to the site wide Central Monitoring System. This data can now be utilized by the ventilation engineer to create realtime ventilation simulations and trends which assist in the prediction and mitigation of NVP and psychrometric related events.

\section{INTRODUCTION}

The Waste Isolation Pilot Plant (WIPP) is designed to permanently isolate from the biosphere radioactive waste left from the research and production of nuclear weapons. The WIPP is located in southeastern New Mexico, 43 kilometers (26 miles) east of Carlsbad. Project facilities include disposal rooms excavated in an ancient (approximately 225 million years old) stable salt formation

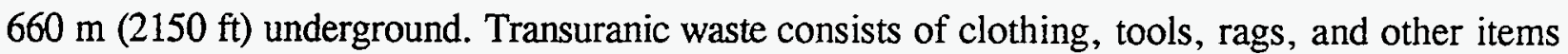
contaminated with trace amounts of radioactive elements, mostly plutonium.

The underground ventilation system is engineered, in addition to its standard functions, to prevent the release of radioactive contamination in the event of an accident. The ventilation system at the is designed to perform two distinct functions. First, it fulfills normal mine ventilation requirements compliance with all state and federal mine regulations. Second, it prevents the uncontrolled release of radioactive contaminants from the facility. Although a nuclear radiation release in the facility is considered very unlikely, the ventilation system incorporates many special features to prevent the spread of and postulated contamination.

A series of psychrometric monitoring stations, referred to as Mine Weather Stations (MWSs) were 
installed in the facility in 1989 to collect psychrometric data on the underground ventilation system. These data were subsequently used to calculate the Natural Ventilation Pressure (NVP). The original system, which was battery operated, stored information locally on a storage module. The data was manually retrieved and brought to the ventilation engineer for downloading to a computer for subsequent analysis. The manual retrieval of the MWS data was a weak link in the project's efforts to provide real time monitoring and modeling capability for underground ventilation system. To enhance the operability of the underground ventilation system, and to use the real time ventilation data, the WIPP has upgraded the MWSs to interface with the site-wide Central Monitoring System (CMS).

\section{DESCRIPTION OF THE VENTILATION SYSTEM}

The underground facility is accessed and ventilated through four vertical shafts, three of which act as intake air supplies, and the fourth is the common exhaust. The three intake shafts at WIPP are the Waste Handling Shaft (WS), Salt Handling Shaft (SHS), and Air Intake Shaft (AIS). The Exhaust Shaft (ES) is the only return airway. During normal operation most of the intake air flows underground through the AIS. The SHS, which provides personnel and material access, is used for the removal of the mined salt and is a secondary intake shaft. The WS is equipped with an enclosed headframe and is used for lowering the waste to the repository horizon. This shaft also serves as the air intake for the WS station and provides access for personnel and materials to the repository horizon. The WS air is isolated from the rest of the repository and is routed directly to the ES after ventilating the shaft station area.

Underground ventilation at WIPP is accomplished with four main ventilation splits called the North area, Mining area, Waste Storage area, and the WS station. In order to minimize occupational exposure of underground personnel to radiation and radioactive materials, the facility is designed and constructed based on the "As Low As Reasonably Achievable" (ALARA) concept. 
This concept resulted in a design where the nuclear waste transportation and storage areas are separated from the mining and non-radioactive experimental areas. The ventilation system is also designed such that air leaks from the Mining and North areas into the Waste Storage areas. Furthermore, radiation detectors are strategically located throughout the underground, and an exhaust filtration system on surface minimizes the possible release of radiation to the environment.

Ventilation through the facility is supplied by running either one or both $450 \mathrm{~kW}$ (600 hp) centrifugal main fans. During concurrent mining and waste handling operations (Normal Ventilation Mode) both fans operate in parallel to provide $230 \mathrm{~m}^{3} / \mathrm{s}(490,000 \mathrm{cfm})$. When either mining or waste emplacement is not taking place (Alternate Ventilation Mode), the ventilation demand is decreased and only one main fan is operated resulting in an airflow of $140 \mathrm{~m}^{3} / \mathrm{s}$ $(300,000 \mathrm{cfm})$. In the unlikely event of an underground radioactive release, the ventilation system is shifted to Filtration Mode, where the airflow is reduced to $28 \mathrm{~m}^{3} / \mathrm{s}(60,000 \mathrm{cfm})$. This airflow is achieved by turning off the main fans and starting one of three $175 \mathrm{~kW}$ (235 hp) centrifugal stand-by filtration fans. A series of isolation dampers divert the air through the filtration system. The air is routed through a series of High Efficiency Particulate Air (HEPA) filters.

\section{REMOTE MONITORING AND CONTROL CAPABILITIES}

Two remote monitoring systems are in place at the WIPP to collect data on the status of the underground ventilation system. The first is the Mine Weather Stations (MWSs) to collect psychrometric data for calculating natural ventilation pressures and air moisture content. These

monitoring stations collect data on temperature (in ${ }^{\circ} \mathrm{C}$ ), pressure (in $\mathrm{kPa}$ ) and relative humidity (in \%). The second is the Underground Ventilation Remote Monitoring and Control System (UVRMCS). It consists of 15 air velocity sensors (in $\mathrm{ft} / \mathrm{min}$ ), eight differential-pressure sensors (in inches water gauge (w.g.)), and provides local and remote indication of the position (percent open) of the air regulators controlling the four ventilation splits. The CMR operator can use 
the control functions of the system to open or close the main regulators from the surface (provided they are set in the field for remote operation).

\section{BENEFITS OF THE REMOTE MONITORING SYSTEM}

In its efforts to provide real time monitoring and modeling capability of the underground ventilation system, the WIPP has designed systems emphasizing interactive capabilities and multiple uses for the data. The availability of real time data from the MWS system provides for a variety of beneficial uses. The data collected by the MWSs can then be subsequently used in: 1) NVP calculations, 2) WIPPVENT, an interactive mine ventilation simulation software program, and 3) psychrometric calculations such as moisture content. All data collected from each MWS is eventually sent to the PI System ${ }^{\mathrm{TM}}$, a data collection, screening, trending, and archival program developed by Oil Systems Inc.

\section{DESIGN AND OPERATION OF MINE WEATHER STATIONS}

\section{System Layout}

The MWS (and UVRMCS) sensors send either a 0-5VDC or a 4-20 mA signal to one of seven Local Processing Units (LPUs ) (three on the surface and four in the underground repository). Each signal or "point" has a specific identifier that the LPU software recognizes which in turn converts the signal to its appropriate engineering unit. The LPUs then transmit the signal onto the Data Highway which extends throughout the facility and terminates at the surface Central Monitoring Room (CMR). The CMR is equipped with Operator-Machine Interface (OMI) terminals. A CMR operator can selectively retrieve the signals from the Data Highway and display them on the OMI terminal in graphical or tabular formats as programmed into the OMI software. The ventilation engineer can retrieve real time data by interfacing to the CMS through a computer program called PI Process Book ${ }^{\mathrm{TM}}$, commercially available from Oil Systems Inc. PI is an archival program which collects data, screens them, and eventually archives them to the VAX for 
final storage. The PI system connects to the site CMS through computer drivers developed by Oil Systems Inc. Figure 1 shows the relationship between the MWS, UVRMCS, LPU's, CMR, OMI, VAX network, and the ventilation engineer's terminal.

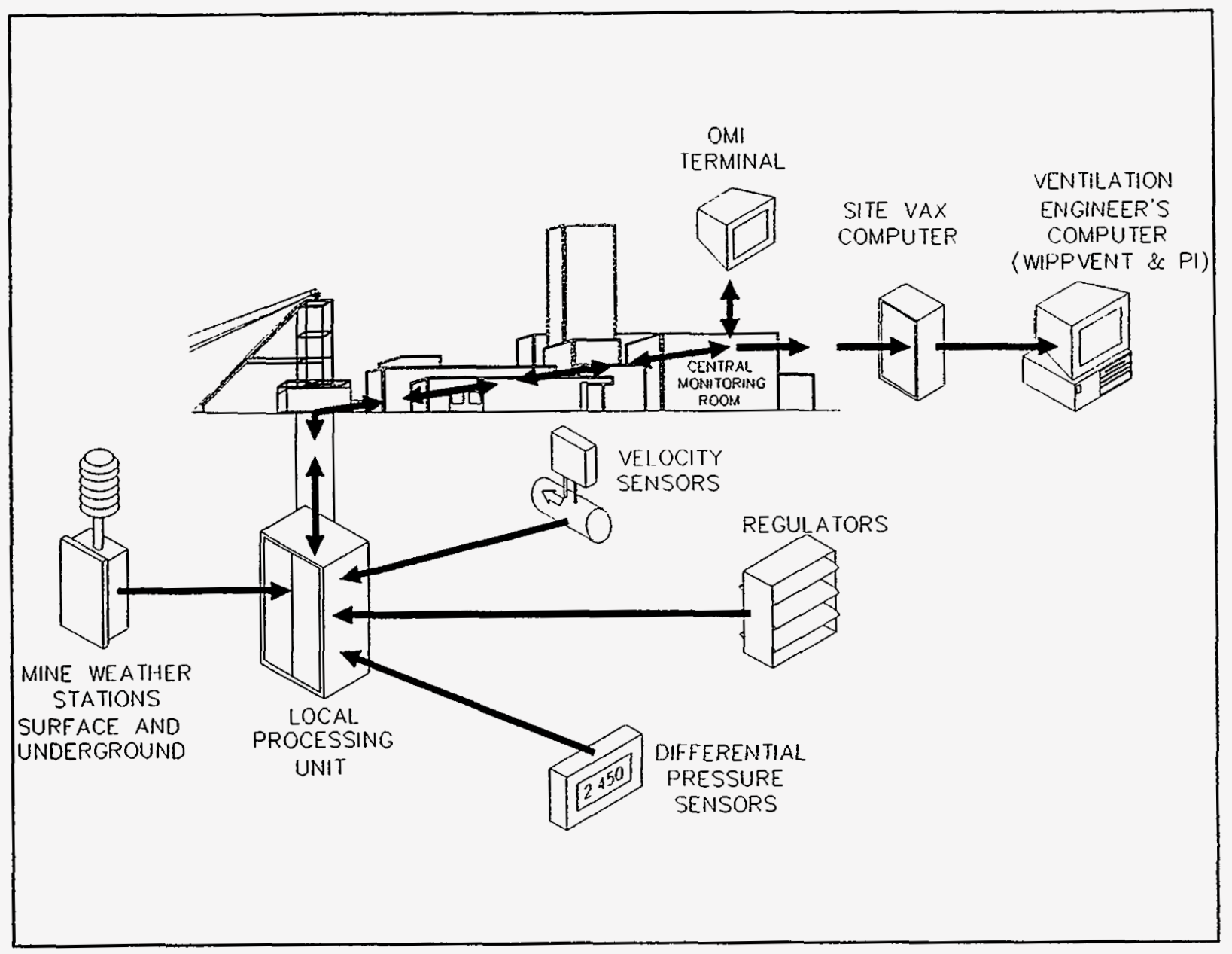

Figure 1: Relationship between the MWS, UVRMCS, LPUs, CMR, OMI, VAX network, and the ventilation engineers terminal.

\section{Major Elements}

The MWS consist of four primary components. Temperature and relative humidity are measured in the $-35^{\circ} \mathrm{C}$ to $50^{\circ} \mathrm{C}$ and $0-100 \%$ ranges by a Viasala HMP35C Probe ${ }^{\text {T3 }}$. Pressure is measured in the 800-1060 mBar range by a Viasala PTA 427 Barometric Pressure Sensor ${ }^{\mathrm{TS}}$. The brain of the 
MWS is a Campbell Scientific Inc. CR10 Measurement and Control System ${ }^{\text {th}}$ (data logger). This unit receives analog signals from the sensors and stores them internally for subsequent use. The raw data are manipulated into a suitable form through the use of specifically designed program using Campbell Scientific Inc. PC208 ${ }^{\mathrm{rm}}$ software. Finally, the data signals are converted into units compatible with the CMS software and scaled to a 0-5000 mV range for output . The output signal is then generated by a Campbell Scientific Inc. SDMA04 Analog Output Module ${ }^{\text {TM }}$. This device is capable of sending four $0-5000 \mathrm{mV}$ signals to the CMS based on a 0-5000 unit input signal from the PC208 software. Sixteen of these units can be tied in series, with each one having its own unique identity. Several of the MWS are located too distant from the LPU for a 0-5 VDC signal to travel without degrading signal quality. These units are equipped with a Hathaway XZ2-D ${ }^{\text {th }}$, 0-5 VDC to 4-20 mA signal converter. Because the WIPP uses imperial units, the result of this process is data available in the CMS in the form of: temperature in degrees Fahrenheit $\left({ }^{\circ} \mathrm{F}\right)$, pressure in inches mercury (in. $\mathrm{Hg}$ ), and relative humidity in percent (\%). In addition to the system components, the MWS units were upgraded with 24 VDC power supplies and tricklecharged battery backups. The SDMA04 requires a system impedance of 50,000 ohms in order to maintain signal quality. 50,000 ohm resistors were added to the LPU to provide the necessary impedance. A 5:1 voltage split was achieved to transform the 0-5 VDC signal output from the SDMA04 into a 0-1 VDC signal suitable to the LPU.

\section{Signal Output/Performance}

The units were field-tested for accuracy against both the final signal reading in the CMS and a calibrated hand-held measurement device. In order to assure that the LPU/CMS system was functioning properly prior to connecting the MWS, each termination point within the LPU was tested, and the corresponding signal in the CMS verified. Signals of zero (0) and five (5) VDC were sent to verify the top and bottom range for each signal. Signals anticipated in the CMS were: temperature in the range of -27.4 to $118.4{ }^{\circ} \mathrm{F}$, relative humidity in the range of 0 to 100 percent, and pressure in the range of 23.624 to 31.302 in.w.g. The zero and five volt signal transmitted 
was received in the CMS with greater than $99.5 \%$ accuracy in all cases.

Once the SMDA04 was connected to the LPUs, the actual outputs $(0-5000 \mathrm{mVDC})$ for each signal were verified in the CMS. The signal recorded by the Campbell CR10 corresponded to the signal received in the CMS by greater than $95 \%$ in all cases. The same measured value being sent to the CMS was also checked with a calibrated hand held instrument. The temperature and relative humidity were measured by a Solomat 500E Multi Probe Meter ${ }^{\text {Th }}$. The pressure was measured by a Setra Model 370 Digital Pressure Gage ${ }^{\mathrm{Th}}$. In most cases, the value recorded by the Campbell correlated to a hand held instrument by greater than $95 \%$. Some additional allowances were made for situations where, for safety reasons, the hand- held instrument could not be placed in the same location as the permanently mounted probe (such as below a shaft collar). Even in these cases, the correlation was greater than $90 \%$.

\section{DISCUSSION OF BENEFITS OF REALTIME DATA}

Several applications at the WIPP will directly benefit from the availability of real time psychrometric data.

\section{NVP}

The calculation of NVP from real time data will enable the creation of true real time ventilation simulation models (in conjunction with data from the UVRMCS). Live data trends on the psychrometric conditions in the underground will assist in the prediction and mitigation of related events.

NVP can significantly effect the normal operation of the WIPP underground ventilation system. At different times of the year, seasonal extremes can act to either assist or impede the operation of the main fans. This can have a significant effect on the operation of the WIPP underground ventilation system. 
During hot weather, the air entering the underground is warmer and less dense than the air returning from the underground. Hence, in hot weather the NVP which the fan pressure. This reduces the flow and reduces the differential pressures between the WS station, Waste Storage area, and the other repository areas. The air in the WS will be cooler than that in the AIS and SHS which further reduces the Waste Shaft station to Mining area differential pressure.

During cold weather, the air entering the underground is colder and denser than the air returning from the underground. Hence, in cold weather there is an NVP which augments the fan pressure. The positive NVP reduces the fan (constant flow control) suction pressure, increases the downcast air flow in one or more air shafts and increases the differential pressure between the WS station, Waste Storage area, and the other areas. The air feeding the WS is warmer than the surface air feeding the AIS. The consequences of this are a reduction in flow down the WS and possible reverse flow in the WS. Administrative actions are taken to adjust the underground regulators to avoid reverse flow in the WS. Cold Weather NVP can also cause lower flow velocities in the SHS compared to the AIS and can potentially cause the SHS flow to reverse.

\section{WIPPVENT}

WIPPVENT is an interactive mine ventilation simulation software program developed by Westinghouse Electric Corporation for exclusive use at the Waste Isolation Pilot Plant. It is based on the commercially available VNETPC Version 3.1 (copyright (c) 1991, Mine Ventilation Services, Inc.). The characteristic which makes WIPPVENT unique is that it is designed to interact with the WIPP underground ventilation monitoring systems (the UVRMCS and the MWS) through the sitewide CMS. Data from the remote monitoring systems is accessed directly from the CMS and the PI System and used by WIPPVENT to calculate the NVP. Furthermore, WIPPVENT also incorporates characteristic resistance curves specific to the site's four main underground regulators . These features give WIPPVENT the ability to retrieve real time data and to use these data to create and continuously update a real time ventilation model. In addition to being utilized for NVP 
calculations (and subsequent modeling via WIPPVENT), the archived psychrometric data from the MWS are available on PI for analysis of either real time or historical trends.

\section{Psychrometric Calculations}

One future enhancement of the system which is being developed is to calculate the mass flow of water into and out of the facility. The calculations necessary to transform temperature, relative humidity and pressure into mass flow are programmed directly into the PI software. Each set of psychrometric data from the MWS will eventually result in the mass flow of moisture at that location in kilograms/second and gallons/minute. Initial enhancements are concentrated on achieving this at the top and bottom of the ES. This will enable the amount of moisture which is being precipitated out of the air stream (or evaporated) to be trended. Additional enhancements will expand this approach to all of the MWSs throughout the facility.

\section{SUMMARY}

The Mine Weather Station system installed at the Waste Isolation Pilot Plant has been successfully integrated with the CMS to provide an effective means of monitoring NVP and psychrometric related events. Real time monitoring helps to assure effective mitigation and/or administrative control of NVP or other psychrometric related events, which further enhances the operation of the WIPP. The system will later be augmented with the capability to calculate and trend moisture flow in the ES, and eventually throughout the facility.

Processing and final preparation of this paper was performed by Westinghouse Electric Corporation, Waste Isolation Division, the management and operating contractor for the Waste Isolation Pilot Plant under U.S. Department of Energy contract number DE-AC04-86AL31950. This document has been submitted as required to:

Office of Scientific and Technical Information

P. O. Box 62

Oak Ridge, TN 37831

(615) $576-8401$

Additional Information about this document may be obtained by calling (800) 336-9477. Copies may be obtained by contacting the National Technical Information Service, US Department of Commerce, 5285 Port Royal Road, Springtield, VA 22101. 


\section{REFERENCES}

Campbell Scientific, Inc., 1991, "SDM-A04 Four Channel Analog Output Module Instruction Manual" Campbell Scientific Inc., Logan, Utah

Campbell Scientific, Inc., 1991, "PTA-427 Barometric Pressure Transducer Operators Manual, Revision 5/94", Campbell Scientific Inc., Logan, Utah.

Campbell Scientific, Inc., 1991, "Model HMP35C Temperature and Relative Humidity Probe Instruction Manual, Revision 5/94" Campbell Scientific Inc., Logan, Utah.

Campbell Scientific, Inc., 1991, "CR10/PC208 Training Manual, Revision 4/93", Campbell Scientific Inc., Logan, Utah.

McDaniel, K.M. and Wallace, K.G. 1996. "The Development of WIPPVENT, An Interactive Mine Ventilation Simulation Computer Program at the Waste Isolation Pilot Plant". The 1996 Annual Meeting and Exhibit of the Society of Mining Engineers of the American Institute of Mining, Petroleum and Metallurgical Engineers, Phoenix, Arizona, March 1996.

Strever, M.T., Wallace, K.G., and McDaniel, K.M. 1995, "Underground Ventilation Remote Monitoring and Control System", Proceedings of the 7th U.S. Mine Ventilation Symposium, June 57, 1995, Chapter 11, SME Inc., pp. 69-74. 